\title{
PENGEMBANGAN LEMBAR KERJA SISWA BERORIENTASI KECAKAPAN HIDUP PADA MATERI SISTEM INDERA MANUSIA UNTUK SISWA SMA KELAS XI
}

\section{THE DEVELOPMENT OF STUDENT WORKSHEET ORIENTATED TO LIFE SKILL ON HUMAN SENSE SYSTEM FOR SENIOR HIGH SCHOOL GRADE ELEVEN}

\author{
Fatra Hadi Kurniawan ${ }^{1}$, Reni Istiningrum ${ }^{2}$, Saila Alfiatin Nuha ${ }^{3}$ \\ Prodi Teknologi Pembelajaran \\ Pascasarjana Universitas Negeri Malang \\ Email: ${ }^{1}$ fatra.tep.um@gmail.com, ${ }^{2}$ reremoedbgt@gmail.com, ${ }^{3}$ saila.alvi@gmail.com
}

\begin{abstract}
The rule of education ministry and BSNP strengthen that the curriculum of formal and non-formal educations have the importance to develop learning which is oriented to life skill. The skill has its purpose to reach the students' competence for their survival and adaptation in order to be successful in their life. Based on this explanation, the researcher developed a student worksheet which is oriented to life skill using 4-D model. The goal of the development of the student worksheet oriented to life skill which is practiced and can be prepared at school. The results showed that the worksheet valid from identity component, technical, construction, content and the life skill characteristics. The students' positive response to the student worksheet which is oriented to life skill reach $84 \%$ with a good category.
\end{abstract}

Keyword: Student Worksheet, Life skill, Human Sense

Abstrak- Peraturan Menteri Pendidikan dan BSNP memperkuat bahwa kurikulum sekolah formal maupun non-formal memiliki kepentingan untuk mengembangkan pembelajaran berorientasi kecakapan hidup (life skill). Kecakapan tersebut bertujuan untuk mencapai kompetensi peserta didik untuk bertahan hidup serta menyesuaikan diri agar berhasil dalam kehidupan. Berdasarkan penjelasan tersebut peneliti mengembangkan LEMBAR KERJA SISWA berorientasi kecakapan hidup dengan model 4D. Tujuan pengembangan LEMBAR KERJA SISWA berorientasi kecakapan hidup materi sistem indera manusia yang praktis dan dapat disiapkan di sekolah. Hasil penelitian menunjukkan bahwa LEMBAR KERJA SISWA valid adalah dari dari komponen identitas, teknis, konstruksi dan karakteristik kecakapan hidup. Respon positif siswa terhadap LEMBAR KERJA SISWA berorientasi kecakapan hidup sebesar $84 \%$ dengan kategori baik.

Kata kunci: Lembar Kerja Siswa, kecakapan hidup, Sistem Indera Manusia

\section{PENDAHULUAN}

Kurikulum secara yuridis diamanatkan oleh Undang-Undang Nomor 20 Tahun 2003 tentang Sistem Pendidikan Nasional dan Peraturan Pemerintah Republik Indonesia Nomor 19 Tahun 2005 tentang Standar Nasional Pendidikan. Penyusunan kurikulum oleh sekolah dimulai tahun ajaran 2007/2008 dengan mengacu pada Standar Isi (SI) dan Standar Kompetensi Lulusan (SKL) untuk pendidikan dasar dan menengah sebagaimana yang diterbitkan melalui Peraturan Menteri Pendidikan Nasional tiap-tiap Nomor 22 Tahun 2006 dan Nomor 23 Tahun 2006, serta Panduan Pengembangan KURIKULUM yang dikeluarkan oleh Badan Standar Nasional Pendidikan (BSNP). Kurikulum ini menempatkan siswa sebagai pusat pembelajaran yang diharapkan mampu berperan aktif dalam proses belajar mengajar. Siswa diharapkan mampu belajar mandiri dan kreatif serta mampu menyelesaikan masalah dengan pengetahuan yang dimilikinya.

Posisi pendidikan kecakapan hidup ini diperkuat dengan terbitnya PP nomor 19 Tahun 2005 Pasal 13 seperti yang tersurat pada ayat (1) dinyatakan bahwa "Kurikulum untuk SD/MI/SDLB, SMP/MTs/SMPLB,
SMA/MA/SMALB, SMK/SMAK atau bentuk lain yang sederajat dapat memasukkan pendidikan kecakapan hidup (life skill)“. Hal itu sejalan dengan panduan KURIKULUM yang dikeluarkan oleh BSNP bahwa kurikulum untuk semua jenjang pendidikan formal maupun non-formal dapat memasukkan pendidikan kecakapan hidup (life skill). Atas dasar itu, baik sekolah formal maupun non-formal memiliki kepentingan untuk mengembangkan pembelajaran berorientasi kecakapan hidup (life skill). Kecakapan hidup (life skill) adalah kecakapan yang dimiliki seseorang untuk mau dan berani menghadapi permasalahan hidup dan penghidupan secara wajar tanpa merasa tertekan kemudian secara proaktif dan kreatif mencari serta menemukan solusinya sehingga akhirnya mampu mengatasinya (Tim BBE Depdiknas, 2001 dalam Arifin, 2007).

Materi pokok sistem indera merupakan salah satu dari materi yang berkaitan dengan masalah-masalah di kehidupan sehari-hari siswa, yaitu terkait dengan fungsi sistem indera bagi manusia, mekanisme kerja sistem indera dan gangguan pada sistem indera manusia. Siswa perlu mengetahui apa fungsi sistem indera manusia, bagaimana mekanisme kerja sistem indera dan bagaimana jika terjadi gangguan terhadap sistem indera kemudian apa dampaknya bagi tubuh. Masalah-masalah 
di kehidupan sehari-hari siswa yang berkaitan dengan materi pelajaran tersebut dapat diselesaikan melalui kecakapan hidup, baik dalam hal mengambil keputusan dengan tepat ataupun mencari solusi yang tepat untuk menyelesaikan masalah tersebut, sehingga dapat melatih kecakapan rasional siswa dan dalam proses mencari solusi atau informasi dapat dilakukan dengan cara berdiskusi atau bekerjasama sehingga secara tidak langsung dapat melatih kecakapan sosial siswa. Oleh karena itu, pengalaman belajar siswa dalam menggunakan LEMBAR KERJA SISWA berorientasi kecakapan hidup dapat melatihkan siswa untuk menerapkan ke dalam kehidupannya. Dari keunggulan tersebut, maka peneliti ingin mengembangkan LEMBAR KERJA SISWA Life Skill dengan materi yang berbeda, dalam kesempatan ini tentang sistem indera, dengan harapan dapat memperoleh hasil yang baik.

Berdasarkan latar belakang permasalahan tersebut, maka rumusan permasalahan yang diajukan dalam proposal ini adalah Bagaimanakah validitas LEMBAR KERJA SISWA berorientasi kecakapan hidup (life skill) pada materi sistem indera yang dikembangkan?

Berdasarkan rumusan masalah tersebut, tujuan dari penelitian ini adalah mengembangkan LEMBAR KERJA SISWA berorientasi kecakapan hidup (life skill) pada materi sistem indera yang memenuhi validitas.

\section{METODE PENELITIAN}

Penelitian ini merupakan sebuah penelitian pengembangan dengan mengacu pada model pengembangan 4-D. Model pengembangan 4-D meliputi empat tahap, yaitu define, design, develop, dan dissseminate. Tahap disseminate tidak dilakukan karena penelitian ini difokuskan pada pengembangan. Penelitian ini dilakukan pada bulan Januari 2012-Juli 2013 di Universitas Negeri Surabaya dan ujicoba terbatas LEMBAR KERJA SISWA yang dilakukan pada bulan Agustus 2013 di SMAN 1 Kediri. Instrumen yang digunakan adalah lembar kelayakan LEMBAR KERJA SISWA yang ditelaah oleh 2 pakar biologi dan 1 guru biologi. Lembar Kerja Siswa dikatakan valid secara teoritis jika skor rata-rata dari hasil validasi sebesar $\geq$ 2,51, lembar penilaian kecakapan berpikir rasional siswa dan lembar kecakapan sosial siswa dan lembar angket respon siswa terhadap LEMBAR KERJA SISWA berorientasi kecakapan hidup.

\section{HASIL DAN PEMBAHASAN}

Hasil penelitian pengembangan LEMBAR KERJA SISWA berorientasi kecakapan hidup (life skill) untuk SMA kelas XI materi sistem indera manusia meliputi hasil validasi dan hasil uji coba LEMBAR KERJA SISWA tersebut. Peneliti memperoleh saran dari dosen pembimbing pada tahap define dan design yang meliputi tahap analisis depan belakang, penyusunan LEMBAR KERJA SISWA dan desain awal LEMBAR KERJA SISWA sehingga menghasilkan draf I. Selain itu, peneliti juga memperoleh saran dari dosen penyanggah dan penelaah untuk kesempurnaan LEMBAR KERJA SISWA berorientasi kecakapan hidup. Berikut ini adalah hasil validitas LEMBAR KERJA SISWA berorientasi kecakapan hidup:

Tabel 1. Hasil Validitas LEMBAR KERJA SISWA

\begin{tabular}{|c|c|c|c|c|c|c|}
\hline \multirow{2}{*}{ No } & \multirow{2}{*}{ Kriteria } & \multicolumn{3}{|c|}{ Penilaian } & \multirow{2}{*}{$\begin{array}{c}\text { Skor } \\
\text { rata-rata }\end{array}$} & \multirow{2}{*}{$\begin{array}{l}\text { Kate } \\
\text { gori }\end{array}$} \\
\hline & & P1 & $\mathrm{P} 2$ & P3 & & \\
\hline A. & \multicolumn{6}{|l|}{ IDENTITAS } \\
\hline 1. & $\begin{array}{l}\text { Kesesuain topik pada } \\
\text { LEMBAR } \\
\text { SISWA dengan pokok } \\
\text { bahasan }\end{array}$ & 4 & 4 & 4 & \multirow{3}{*}{3,8} & \multirow{3}{*}{$\begin{array}{l}\text { Sang } \\
\text { at } \\
\text { baik }\end{array}$} \\
\hline 2. & $\begin{array}{l}\text { Mencantumkan tujuan } \\
\text { pembelajaran yang ingin } \\
\text { dicapai }\end{array}$ & 4 & 3 & 4 & & \\
\hline 3. & $\begin{array}{l}\text { Mencantumkan petunjuk } \\
\text { penggunaan LEMBAR } \\
\text { KERJA SISWA }\end{array}$ & 4 & 4 & 4 & & \\
\hline B. & \multicolumn{6}{|l|}{ TAMPILAN/TEKNIS } \\
\hline 1. & $\begin{array}{l}\text { Kesesuaian tulisan dan } \\
\text { huruf }\end{array}$ & 3 & 2 & 4 & \multirow{4}{*}{3,5} & \multirow{4}{*}{$\begin{array}{l}\text { Sang } \\
\text { at } \\
\text { baik }\end{array}$} \\
\hline 2. & $\begin{array}{l}\text { Kesesuaian cover dengan } \\
\text { topik }\end{array}$ & 4 & 3 & 4 & & \\
\hline 3. & $\begin{array}{l}\text { Tampilan gambar dan } \\
\text { warna pada LEMBAR } \\
\text { KERJA SISWA menarik } \\
\text { peserta didik }\end{array}$ & 4 & 3 & 4 & & \\
\hline 4. & $\begin{array}{ll}\text { Kesesuaian tata } & \text { letak } \\
\text { dengan konsep } & \text { yang } \\
\text { diinginkan } & \\
\end{array}$ & 4 & 3 & 4 & & \\
\hline C. & $\begin{array}{l}\text { BAHASA/KONSTRUK } \\
\text { SI }\end{array}$ & & & & & \\
\hline 1. & $\begin{array}{l}\text { Kalimat yang digunakan } \\
\text { jelas, operasional, dan } \\
\text { tidak menimbulkan } \\
\text { makna ganda }\end{array}$ & 4 & 3 & 4 & \multirow[t]{2}{*}{3,8} & \multirow{2}{*}{$\begin{array}{l}\text { Sang } \\
\text { at } \\
\text { baik }\end{array}$} \\
\hline 2. & $\begin{array}{l}\text { Bahasa yang digunakan } \\
\text { mudah di mengerti oleh } \\
\text { peserta didik }\end{array}$ & 4 & 4 & 4 & & \\
\hline D. & \multicolumn{6}{|l|}{ ISI } \\
\hline 1. & $\begin{array}{l}\text { Memenuhi } \\
\text { didaktik }\end{array}$ & 3 & 4 & 3 & \multirow{3}{*}{3,6} & \multirow{3}{*}{$\begin{array}{l}\text { Sang } \\
\text { at } \\
\text { baik }\end{array}$} \\
\hline 2. & $\begin{array}{l}\text { Materi yang disampaikan } \\
\text { sesuai dengan konsep }\end{array}$ & 4 & 4 & 4 & & \\
\hline 3. & $\begin{array}{l}\text { Materi sesuai dengan } \\
\text { indikator dan tujuan } \\
\text { pembelajaran }\end{array}$ & 4 & 3 & 4 & & \\
\hline E. & \multicolumn{6}{|c|}{ KARAKTERISTIK KECAKAPAN HIDUP } \\
\hline 1. & $\begin{array}{l}\text { Mencantumkan } \\
\text { kecakapan hidup sosial }\end{array}$ & 4 & 4 & 4 & \multirow{3}{*}{4} & \multirow{3}{*}{$\begin{array}{l}\text { Sang } \\
\text { at } \\
\text { baik }\end{array}$} \\
\hline 2. & $\begin{array}{l}\text { Mensubtitusikan } \\
\text { kecakapan hidup rasional } \\
\text { (menggali informasi, } \\
\text { mengolah informasi) }\end{array}$ & 4 & 4 & 4 & & \\
\hline 3. & $\begin{array}{l}\text { Mencantumkan } \\
\text { kecakapan hidup yang } \\
\text { dilatihkan pada petunjuk } \\
\text { LEMBAR } \\
\text { SISWA }\end{array}$ & 4 & 4 & 4 & & \\
\hline
\end{tabular}

Komponen kelayakan isi divalidasi oleh 2 pakar biologi dan 1 guru biologi menunjukkan bahwa kelengkapan penjelasan pada uraian materi serta gambar yang diperjelas, kebenaran konsep, perbaikan pada petunjuk LEMBAR KERJA SISWA menggali informasi dan mengolah informasi, pertanyaan-pertanyaan yang mencerminkan kecakapan hidup rasional menggali informasi dan mengolah informasi, serta penulisan daftar pustaka. 
Kelengkapan penjelasan pada uraian materi bertujuan agar informasi yang diterima oleh siswa lengkap dan jelas. Kebenaran konsep tentang sistem indera perlu beberapa perbaikan agar tidak terjadi miskonsepsi. Saran perbaikan oleh dosen penyanggah untuk LEMBAR KERJA SISWA yaitu perujukan gambar pada teks agar siswa memperoleh informasi dari membaca dan melihat gambar. Hal ini berkaitan dengan syarat teknis yang diadaptasi dari Widodo (2011) yaitu gambar yang baik untuk LEMBAR KERJA SISWA adalah gambar yang dapat menyampaikan isi atau pesan dari gambar secara efektif kepada siswa, tulisan dan penampilan juga harus sesuai. Pertanyaan-pertanyaan yang mencerminkan kecakapan hidup mencerminkan kecakapan hidup rasional menggali informasi dan mengolah informasi diharapkan dapat membantu siswa dalam memahami konsep-konsep dalam materi tersebut serta mengaitkan materi sistem indera dengan kehidupan sehari-hari mereka. Selain itu penulisan daftar pustaka tersebut harus sesuai dengan Tim Penyusun Panduan Penulisan dan Penilaian Skripsi Unesa (2006) yang menyatakan bahwa urutan penulisan unsur-unsur daftar rujukan adalah (a) nama pengarang, (b) tahun terbit, (c) judul sumber yang dirujuk, (d) kota tempat terbit dan (e) nama penerbit. Setelah revisi atau perbaikan LEMBAR KERJA SISWA dari saran-saran tersebut diperoleh draf II.

Setelah diperoleh draf II kemudian draf tersebut divalidasi oleh dosen penelaah. Hasil validasi dapat dilihat pada Tabel 4.1. Pada Tabel 4.1 menunjukkan beberapa saran perbaikan oleh dosen penelaah untuk LEMBAR KERJA SISWA yaitu penggunaan spasi, penulisan istilah dengan huruf miring, penggunaan kata yang sesuai agar tidak ada kalimat majemuk sehingga dapat disesuaikan dengan aturan yang baku. Dengan penulisan yang tepat sesuai dengan aturan yang baku diharapkan agar tidak terjadi salah persepsi oleh siswa. Hal ini berhubungan dengan pernyataan Rusdyanto dalam Widodo (2011) tentang persyaratan konstruksi, persyaratan konstruksi yang harus dipenuhi oleh LEMBAR KERJA SISWA adalah syarat-syarat yang berkenan dengan penggunaan bahasa, susunan kalimat, kesederhanaan pemakaian kata-kata dan kejelasan yang pada hakekatnya haruslah tepat guna dalam arti dimengerti siswa.

Pada tahap validasi, selain saran perbaikan dosen penelaah juga memberikan penilaian berupa skor penilaian seperti yang disajikan pada Tabel 4.1 untuk hasil validasi LEMBAR KERJA SISWA kecakapan hidup siswa yang dipandu LEMBAR KERJA SISWA berorientasi kecakapan hidup (life skill) untuk SMA kelas XI materi sistem indera manusia. Pada tahap tersebut dapat diuraikan bahwa komponen LEMBAR KERJA SISWA identitas yang meliputi kesesuain topik pada LEMBAR KERJA SISWA dengan pokok bahasan, mencantumkan tujuan pembelajaran yang ingin dicapai dan mencantumkan petunjuk penggunaan LEMBAR KERJA SISWA dengan skor rata-rata 3,8. Pada komponen identitas mencantumkan petunjuk penggunaan LEMBAR KERJA SISWA mendapatkan rata-rata skor 4 dengan kategori sangat baik. Hal ini sesuai dengan Depdiknas (2004) bahwa lembar kegiatan biasanya berupa petunjuk dan langkah-langkah untuk menyelesaikan suatu tugas serta petunjuk harus ditulis jelas agar mengurangi pertanyaan dari siswa tentang halhal yang seharusnya dapat dilakukan oleh siswa.

Syarat teknik meliputi kesesuaian tulisan dan huruf, kesesuaian cover dengan topik, tampilan gambar dan warna pada LEMBAR KERJA SISWA menarik peserta didik, kesesuaian tata letak dengan konsep yang diinginkan memperoleh rata-rata 3,5. Syarat teknik yaitu tampilan gambar dan warna pada LEMBAR KERJA SISWA menarik peserta didik memperoleh rata-rata skor 3,67. Pada kesesuaian tulisan dan huruf penelaah masih ada yang memberi nilai 2 karena masih banyak tulisan yang salah ketik dan istilah yang belum dicetak miring. Kesesuaian cover dengan topik dan kesesuaian tata letak dengan konsep yang diinginkan memperolah skor ratarata 3,67 dengan kategori sangat baik. Hal tersebut menunjukkan bahwa kesesuaian cover dengan topik dan kesesuaian tata letak dengan konsep sudah dianggap baik. Jadi syarat teknik mendapat skor terendah dari yang lainnya yaitu 3,5 karena masih banyak tulisan yang salah ketik dan istilah yang belum dicetak miring.

Komponen bahasa/konstruksi yang meliputi Kalimat yang digunakan jelas, opersional, dan tidak menimbulkan makna ganda, serta bahasa yang digunakan mudah di mengerti oleh peserta didik memperoleh skor rata-rata 3,8 dengan kategori sangat baik yang dinilai dari kalimat yang digunakan dan bahasa yang digunakan pada rangkuman materi dan pertanyaan pada LEMBAR KERJA SISWA. Hal ini berarti secara bahasa kalimat sesuai dengan kaidah bahasa Indonesia yang benar dan penggunaan istilah sudah tepat dan konsisten. Hal tersebut sesuai dengan Depdiknas dalam Rusdiana (2010) bahwa syarat konstruksi meliputi syarat-syarat yang berkenaan dengan penggunaan bahasa, susunan kalimat, kesederhanaan pemakaian kata-kata, dan kejelasannya tepat guna dapat dimengerti siswa.

Komponen isi meliputi memenuhi syarat didaktik, materi yang disampaikan sesuai dengan konsep, materi sesuai dengan indikator dan tujuan pembelajaran memperoleh skor rata-rata 3,6 dengan kategori sangat baik. Hal tesebut menunjukkan bahwa isi LEMBAR KERJA SISWA pada LEMBAR KERJA SISWA sudah valid karena sudah memenuhi komponen isi tersebut. Komponen karakteristik kecakapan hidup memperoleh skor rata-rata 4 dengan kategori sangat baik yang dinilai dari mencantumkan kecakapan hidup sosial, mensubtitusikan kecakapan hidup rasional (menggali informasi dan mengolah informasi) dan mencantumkan kecakapan hidup yang dilatihkan pada petunjuk LEMBAR KERJA SISWA.

Peneliti telah mencantumkan kecakapan hidup sosial pada tujuan pembelajaran afektif. Hal ini dapat dilihat pada tujuan pembelajaran di LEMBAR KERJA SISWA. Pada komponen uraian materi, kriteria mudah dipahami dan sesuai dengan materi yang dibahas terpenuhi. Kesesuaian dengan materi yang dibahas dapat membantu siswa untuk lebih mudah dalam memperoleh informasi yang dibutuhkan sehingga memudahkan siswa dalam proses untuk memperoleh konsep. Hal ini sesuai dengan pendapat Depdiknas (2004) bahwa materi LEMBAR KERJA SISWA dapat berupa informasi pendukung yaitu gambaran umum atau ruang lingkup 
substansi yang akan dipelajari. Pada komponen pertanyaan, dua kriteria yang terpenuhi yaitu kriteria sesuai dengan tujuan pembelajaran dan sesuai dengan kegiatan yang telah ditentukan.

Hal tersebut menunjukkan bahwa LEMBAR KERJA SISWA ini sudah valid dan tidak menimbulkan miskonsepsi karena sudah sesuai dengan syarat didaktik, konstruksi dan teknis. Lembar Kerja Siswa ini memperoleh nilai validasi > 2,51 termasuk dalam kategori sangat baik (Sugiyono, 2010) sehingga valid untuk digunakan siswa dalam proses pembelajaran

\section{SIMPULAN}

Berdasarkan hasil analisis dan pembahasan, maka dapat disimpulkan bahwa LEMBAR KERJA SISWA berorientasi kecakapan hidup (life skill) untuk SMA kelas XI materi sistem indera manusia yang telah dikembangkan sudah dikatakan valid oleh penelaah karena sudah memenuhi syarat didaktik, teknis dan konstruksi serta memperoleh kategori sangat baik.

\section{UCAPAN TERIMA KASIH}

Kami mengucapkan terimakasih kepada Nur Qomariyah, S.Pd, M.Sc., Dr. Raharjo, M.Si., Drs. Nyoto Pujiadi, S.Pd yang telah berkenan menjadi penelaah LEMBAR KERJA SISWA berorientasi kecakapan hidup pada materi sistem indera manusia.

\section{DAFTAR PUSTAKA}

Arifin, Zainal. 2012. Konsep dan Model Pengembangan Kurikulum. Bandung: Remaja Rosdakarya.

Campbell, Neil A. 2008. Biology Eighth Edition. United States of America: Pearson Benjamin Cummings.

Depdiknas. 2004. Pedoman Umum Pengembangan Bahan Ajar Sekolah Menengah Ke Atas.

Guyton. 1995. Fisiologi Manusia dan Mekanisme Penyakit (Human Physiology and Mechanisms od Disease) Edisi III. Jakarta: Buku Kedokteran EGC.

Harahab, Dini P. 2012. Pengembangan LEMBAR KERJA SISWA Berorientasi Kecakapan Hidup (Life Skill) Untuk SMA Kelas XI Pada Materi Sistem Peredaran Darah Manusia. Skripsi. Surabaya: Universitas Negeri Surabaya.

Kimball, John W. 1988. Biologi Edisi Kelima Jilid 2. Jakarta: Airlangga.

Knight, John F. 1997. Indera Prima. Bandung: Indonesia Publishing House.

Samani, Muchlas dan Hariyanto. 2012. Konsep dan Model Pendidikan Karakter. Bandung: PT. Remaja Rosdakarya.

Mulyasa, E. Kurukulum Tingkat Satuan Pendidikan: Sebuah Panduan Praktis. Bandung: PT. Remaja Rosdakarya.
Nur, Mohammad. 1999. Teori Belajar Pengajaran Berpusat pada Siswa dan Pendekatan Konstruktivis dalam Pengajaran. Surabaya: Unipress.

Ortleb, Edward dan Zike, Dinah.2005. Human Body Systems. United States of America: Glencoe/McGraw-Hill.

Pearce, Evelin C. 2011. Anatomi dan Fisiologi untuk Paramedis. Jakarta: Gramedia.

Purwanto, Ngalim. 2010. Prinsip-prinsip dan Teknik Evaluasi Pengajaran. Bandung: Remaja Rosdakarya.

Riduwan. 2005. Skala Pengukuran Variabel-Variabel Penelitian. Bandung: Alfabeta.

Rusdiana, Eva. 2011. Pengembangan LEMBAR KERJA SISWA Berorientasi Life Skill pada Materi Sistem Pernapasan di SMA Kelas XI. Skripsi(Tidak dipublikasikan). Surabaya: Universitas Negeri Surabaya.

Sagala, Syaiful. 2007. Konsep dan Makna Pembelajaran. Bandung: Alfabeta.

Soewolo. 2003. Fisiologi Manusia. Malang: Universitas Negeri Malang.

Suyono dan Hariyanto. 2012. Belajar dan Pembelajaran. Bandung: Remaja Rosdakarya.

Sugiyono. 2010. Metode Penelitian Pendidikan Pendekatan Kuantitatif, Kualitatif, dan $R \& D$. Bandung : Alfabeta

Syaifuddin. 2006. Anatomi Fisiologi untuk Mahasiswa Keperawatan. Jakarta: EGC.

Tim BBE Depdikbud. 2003. Pola Pelaksanaan Pendidikan Kecakapan Hidup. Surabaya: SIC.

Tim Penyusun. 2006. Panduan Penulisan dan Penelitian Skripsi Universitas Negeri Surabaya. Surabaya: Unipress.

Trianto. 2007. Model Pembelajaran Terpadu dalam Teori dan Praktek. Jakarta: Prestasi Pustaka.

Widodo, Agus. 2011. Pengembangan Lembar Kegiatan Siswa Inkuiri Dengan Model Pembelajaran Kooperatif Tipe Investasi Kelompok Pada Pokok Bahasan Gerak Melingkar Beraturan. Thesis Magister Pendidikan, Universitas Negeri Surabaya.

Vander, Arthur J., Widmaier, Eric, Raff, Hershel, dan Strang, Kevin. 2001. Human Physiology: The Mechanism of Body Function, Eighth Edition. USA: The McGraw-Hill Companies.

Yamin, Martinis. 2011. Paradigma Baru Pembelajaran. Jakarta: Gaung Persada Press. 